\title{
PERCEPÇÃO SOBRE IMPACTOS SOCIOAMBIENTAIS: UM ESTUDO DE CASO NA RESEX LAGO DO CUNIÃ, PORTO VELHO, RONDÔNIA
}

\author{
The perception over environmental impacts: a study case in Resex lago do \\ Cuniã, Porto Velho, Rondônia
}

\begin{abstract}
Luciana dos Santos Carvalho Instituto Federal de Educação Ciência e Tecnologia de Rondônia biolucarvalho@gmail.com

Graziela Tosini Tejas Instituto Federal de Educação Ciência e Tecnologia de Rondônia graziela.tejas@ifro.edu.br

Reginaldo Martins da Silva de Souza Instituto Federal de Educação Ciência e Tecnologia de Rondônia reginaldo.martins@ifro.edu.br

Xênia de Castro Barbosa Instituto Federal de Educação Ciência e Tecnologia de Rondônia xenia.castro@ifro.edu.br
\end{abstract}

Recebido em 09/04/2021

Aceito em 10/05/2021

RESUMO: Esta pesquisa teve como objetivo investigar a percepção ambiental dos jovens de 16 a 24 anos, associados à cooperativa COOPCUNIÃ e residentes na RESEX Lago do Cuniã, Porto Velho, Rondônia. A metodologia utilizada consistiu em uma análise quali-quantitativa, a partir da aplicação de formulários estruturados com questões objetivas e discursivas. A análise dos dados consistiu na identificação: do perfil socioeconômico (idade, escolaridade, economia e fonte de renda), das atividades desenvolvidas na RESEX, e da relação entre os entrevistados, meio ambiente, uso dos recursos naturais e geração de impactos ambientais. Os resultados demonstraram a necessidade de implantação de um sistema de gerenciamento e tratamento de resíduos, acompanhadas por programas de educação ambiental, de fortalecimento do cooperativismo e de capacitação compatíveis com jornada cotidiana dos trabalhos extrativistas e agropecuários desenvolvidos na unidade de conservação.

Palavras-chave: Percepção ambiental; COOPCUNIÃ; Impacto ambiental.

ABSTRACT: The purpose of this research is to investigate the environmental perception of people at age around 16 to 24 that are associated to the cooperative COOPCUNIÃ and live in RESEX Lago do Cuniã, Porto Velho, Rondônia. It was used a methodology that consists in a quantitative-qualitative analysis through the application of forms which are structured with discursive and objective questions. Data analysis consisted in the identification of the socioeconomic profile (age, education level, economy and income source), the activities performed in the RESEX and the relation among the interviewed people, environment, the use of natural resources and the generation of environmental impact. The result showed the need of creating a waste management and treatment system in association with environmental education programs, to strengthen cooperativism and also training activities that are compatible with daily extractive and agricultural/cattle work developed in the environmental conservation unit.

Keywords: Environmental perception; Coopcuniã; Environmental impact. 
PERCEPÇÃO SOBRE IMPACTOS SOCIOAMBIENTAIS: UM ESTUDO DE CASO NA RESEX LAGO DO CUNIÃ, PORTO VELHO, RONDÔNIA

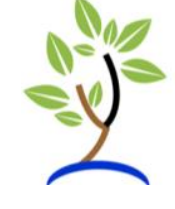

\section{INTRODUÇÃO}

A etimologia do termo percepção tem origem no latim e significa compreensão. $O$ desenvolvimento do conceito nutre estreita relação com o empirismo inglês do final do século XVII. Trata-se da premissa que o conhecimento era concebido como algo adquirido através de métodos de investigação que priorizavam a compreensão dos fenômenos a partir do que se percebia através dos sentidos. Portanto, o arcabouço teórico da percepção pode ser considerado um legado da corrente empirista (GIBSON, 1974; BACHA et al, 2006).

$A$ ocorrência da Percepção está associada às atividades cerebrais e permite, ao ser humano, a formação de ideias e imagens e, consequentemente, a compreensão do mundo que está ao seu redor (MELAZO, 2005; BACHA et al, 2006). Logo, a Percepção é diferente em cada indivíduo é um processo de interação individual com o meio ambiente, estabelecido através da cognição, conforme explicado por Ribeiro (2003).

O conceito de percepção ambiental, no entanto, vem sendo abordado em diversas pesquisas que tratam da problemática sociedade e meio ambiente. São estudos que averiguam qual é a posição do indivíduo perante os acontecimentos do local que o rodeia e a maneira pela qual a sociedade interage com o meio ecológico (COSTA; COLESANTI; 2011). Como a relação entre ser humano e meio ambiente contempla também a dimensão social, científica e política, a investigação sobre a percepção ambiental configura-se como um mecanismo para compreender como os atores sociais adquirem e utilizam conceitos e valores inerentes as suas atitudes e sensibilidade socioambiental. Sendo assim, é possível verificar o escopo do posicionamento do sujeito frente ao uso, a preservação e a conservação do meio ambiente. Por conseguinte, os trabalhos tendem a subsidiar a elaboração de propostas que venham contribuir para melhorias sociais e ambientais, promovendo sustentabilidade (PACHECO; SILVA, 2006; OLIVEIRA; KORONA, 2008). Nesse mesmo sentido, De Paula, Silva e Gorayeb (2014) salientam a importância e a contribuição do entendimento da percepção ambiental dos atores sociais por parte dos planejadores e gestores para a mensuração das limitações e potencialidades das propostas de organização ou reorganização socioespaciais.

O entendimento da percepção sobre os impactos socioambientais em áreas protegidas, como as unidades de conservação, configura-se importante instrumento de gestão e manejo dessas áreas (SHIRAISHI, 2011). O termo impacto foi originado do vernáculo latino impactu e significa choque ou colisão que realiza danos. $\mathrm{Na}$ literatura, é possível encontrar várias conceituações para impacto ambiental sendo, entretanto, a interferência positiva ou negativa do homem no meio ambiente o tronco comum destes conceitos (SANCHEZ,1999; DERANI, 2001). O Conselho Nacional do Meio Ambiente (CONAMA), Resolução 001/86 de 23 janeiro de 1986, art. $1^{\circ}$ considera impacto ambiental como:

Qualquer alteração das propriedades físicas, químicas e biológicas do meio ambiente, causada por qualquer forma de matéria ou energia resultante das atividades humanas que, direta ou indiretamente, afetam a saúde, a segurança e o bem-estar da população; as atividades sociais e econômicas; as condições estéticas e sanitárias do meio ambiente, a biota e a qualidade dos recursos ambientais (BRASIL, 1986, n.p.). 
Doravante, como as questões ambientais e a sociedade estão interligadas e sem chance para desagregar, a perspectiva socioambiental emerge como central na compreensão da realidade social (ALMEIDA, 2004; ALMEIDA; PREMEBIDA; 2014). Os impactos socioambientais, por sua vez, correlacionam a ação do ser humano e meio ambiente. Trata-se da indissolubilidade da ação antrópica, alteração do meio ecológico e perdas sociais, culturais e econômicas (SANTOS, 2008). Portanto, a análise da percepção dos impactos ambientais permite avaliar pontos de vista, as atividades e os agentes sociais que constituem uma determinada organização socioespacial. Sendo que sua realização em unidades de proteção, através do reconhecimento dos aspectos econômico, social e político, possibilitam o estabelecimento de mecanismos de gestão ambiental centrados na pluralidade e na valorização dessas áreas, conforme elucidaram Ferreira (2005) e Souza (2019) ao estudarem a percepção ambiental em unidades de conservação.

Assim, o presente trabalho teve como objetivo geral analisar a percepção dos jovens entre 16 a 24 associados à COOPCUNIÃ e residente na Reserva Extrativista (RESEX) Lago do Cuniã e, sobre os impactos ambientais existentes nessa unidade de conservação. Para tanto, foi necessário: a) caracterizar os jovens entre 16 a 24 anos associados à COOPCUNIÃ sob seus aspectos socioeconômicos; b) reconhecer os problemas ambientais existente na RESEX Lago do Cuniã; c) relacionar as atividades realizadas pelos jovens entre 16 a 24 anos associados à COOPCUNIÃ.

A RESEX Lago do Cuniã é uma unidade de conservação federal de uso sustentável, criada pelo Decreto Federal 3.238 de 10 de novembro de 1999. O seu estabelecimento visar preservar um ecossistema natural de grande relevância ecológica e beleza cênica, garantir o uso dos recursos naturais de forma sustentável e a conservação dos recursos naturais renováveis, tradicionalmente utilizados pela população extrativista da área (ICMBIO, 2018). Está totalmente inserida no município de Porto Velho, RO, acerca de $130 \mathrm{~km}$ do seu centro urbano, o acesso à RESEX pode ser realizado por via fluvial, através do rio Madeira ou via terrestre, através de ramais não pavimentados, dependendo da época do ano, conforme Figura 1. 

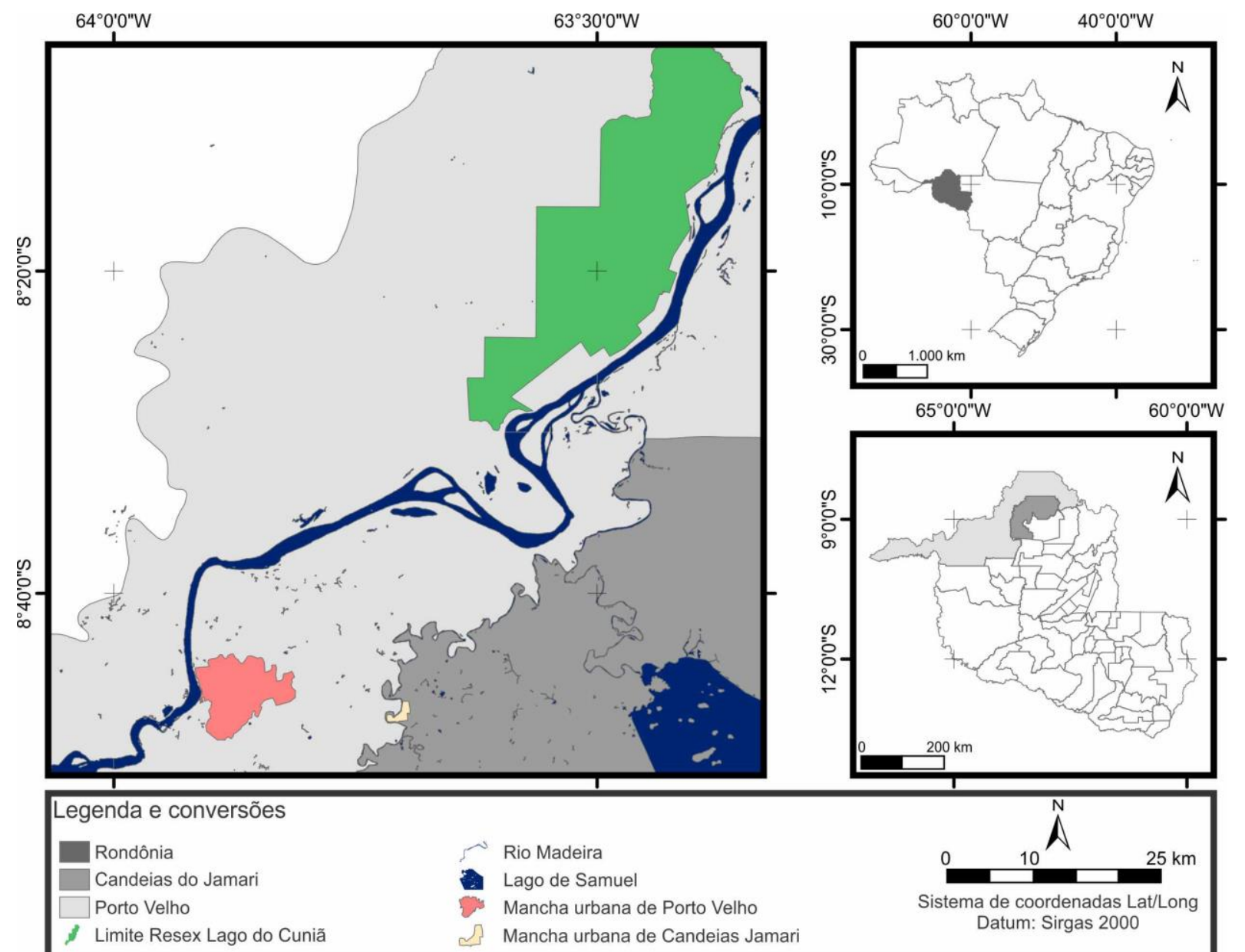

Figura 1. Localização da área de estudo. Organizados pelos Autores.

Fonte: Rondônia (2002).

A ocupação da RESEX Lago do Cuniã tem suas origens no primeiro Ciclo da Borracha (1880) na Amazônia, já que os limites da Reserva se confundem com os do antigo seringal Cuniãzinho, estabelecidos por sua vez, sobre as áreas ocupadas por indígenas da etnia Murá. Portanto, os moradores atuais da RESEX são descendentes da miscigenação de seringueiros amazonenses, nordestinos e indígenas Murá (VALDANHA, 2014). Todavia, na década de 1970, a área da reserva foi inserida no Projeto Integrado de Colonização (PIC), fruto do Projeto de Integração Nacional (PIN), desenvolvido através do INCRA. O objetivo era a criação de uma bacia leiteira na região e o loteamento para fins pecuaristas (VALDANHA, 2014). Na década seguinte, 1980, a permanência dos moradores na localidade foi ameaçada em função da criação de uma Estação Ecológica, unidade de proteção integral, que não permitiria habitação em toda a área de abrangência do lago que nomeia a reserva, a população reagiu à ameaça e conseguindo que parte da estação Ecológica fosse destinada à uma Reserva Extrativista, tipo Unidade de Conservação de uso sustentável que permite a moradia de pessoas. Foi nesse cenário de conflitos pela posse da terra que os comunitários decidem criar a Associação dos Moradores do Cuniã (ASMOCUN). Fundada em julho de 1986, proporcionou à comunidade o sentimento de unidade 
PERCEPÇÃO SOBRE IMPACTOS SOCIOAMBIENTAIS: UM ESTUDO DE CASO NA RESEX LAGO DO CUNIÃ, PORTO VELHO, RONDÔNIA

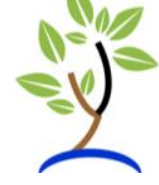

necessário para que o interesse coletivo pela permanência fosse alcançado (DIAS, 2018).

A reserva é ocupada por 92 famílias, conforme IBGE (2010), distribuídas em quatro núcleos. Três estão localizados ao redor do lago do Cuniã que são; Silva Lopes (Alto e Baixo), Neves e Pupunhas. O último é o núcleo Araçá, que fica às margens do Igarapé Grande, que deságua no lago do Cuniã. Em 2010, passou a ser abastecida por energia de uma termelétrica instalada no distrito de São Carlos. A comunidade conta, ainda, com quatro poços artesianos. Apenas com um telefone público, localizado próximo à sede do instituto Chico Mendes de Conservação da Biodiversidade (ICMBio). Porém, os quatros núcleos da RESEX, os moradores possuem acesso à internet em suas residências. Existe apenas um posto de saúde, mantido pela Secretaria Municipal de Saúde de Porto Velho (SEMUSA) sem a presença de equipe médica fixa. Há uma única a escola, Francisco Braga, municipal. Ela oferece aulas para o Ensino Fundamental, e através de parceria com o governo do estado de Rondônia, aulas para o ensino médio (ICMBIO, 2018).

As principais atividades socioeconômicas desenvolvidas na RESEX são: a) os produtos do extrativismo vegetal, agricultura e a pesca. Na primeira destacam-se o açaí (Euterpe oleracea Mart.), e castanha da Amazônia (Bertholletia excelsa). O principal cultivo agrícola é o da mandioca (Manihot esculenta Crantz) da qual se produz a farinha do polvilho e o tucupi, utilizadas principalmente como parte da dieta da população local e excedente comercializado da capital de Rondônia. A pesca também é destinada prioritariamente ao abastecimento familiar com venda significativa de excedentes para o mercado em Porto Velho (DIAS, 2018).

A organização da Cooperativa dos Agricultores e Pescadores do Lago do Cuniã (COOPCUNIÃ) se deu através da articulação da Associação dos Moradores Extrativista da RESEX Cuniã (ASMOCUN), assessorada pelo serviço público de assistência técnica e extensão rural do estado de Rondônia (EMATER), com apoio do ICMBio. Teve como objetivo motivar a comunidade, criar condições para o desenvolvimento de estudos que pudesse qualificar a gestão do empreendimento cooperativo local, bem como a gestão da produção familiar. O foco era agregar valor aos produtos da floresta e o incentivo da produção e comercialização de cultivares agrícolas de ciclo curto (DIAS, 2018).

A (COOPCUNIÃ) foi fundada em 17 de abril de 2011 com 50 sócios fundadores e um capital de $\mathrm{R} \$ 1.000,00$ (um mil reais). A COOPCUNIÃ foi o instrumento escolhido por um grupo de extrativista florestais, pescadores artesanais, agricultores ribeirinhos para efetivar a organização de sua produção na RESEX. Ela tem como foco a sustentabilidade do processo produtivo na atividade econômica de seus sócios de maneira integral e conta com 157 sócios cooperados, sendo que 29 desses sócios são jovens entre 16 e 24 anos (COOPCUNIÃ, 2019). A inclusão dos jovens, a partir dos 16 anos, nas atividades da cooperativa teve como objetivo: a) a contribuição na atividade econômica de caráter familiar. b) direito de participar dos cursos profissionalizantes que seriam ministrados pela Cooperativa com a visão de promover sustentabilidade organizacional e equilíbrio ambiental no futuro. c) participação da família na Gestão de cooperação da COOPCUNIÃ (DIAS, 2018). 
PERCEPÇÃO SOBRE IMPACTOS SOCIOAMBIENTAIS: UM ESTUDO DE CASO NA RESEX LAGO DO CUNIÃ, PORTO VELHO, RONDÔNIA

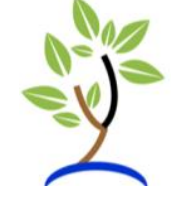

A gestão da COOPCUNIÃ é composta pelas coordenadorias de gestão administrativa, gestão financeira, gestão comercial, gestão social, gestão agroindústria e gestão de planejamento e projetos, além do conselho fiscal, que conta com um Titular e um Suplente. A primeira gestão da cooperativa foi formada por: Antônio Ednaldo Fernandes de Souza, coordenador de gestão administrativa, Scheila Barros da Silva, responsável pela coordenadoria de gestão financeira; Alex de Souza Nogueira, coordenador de gestão comercial; Maria Iris Alves dos Santos, coordenadora de gestão social; Elizângela Araújo, coordenadora de gestão agroindustrial e Domingos Gonçalves Braga. Em 05 de maio de 2019, apesar das atividades parcialmente paralisadas desde de 2016, foi eleita uma nova gestão administra composta pelo senhor Tito Gonçalves Neves, coordenador de gestão administrativo; Ada Neves de Carvalho, coordenadora de gestão financeira; Leila Maria Carmo da Silva, coordenadora de gestão comercial; Ruth Machado de Souza, coordenadora de gestão social; Edina dos Santos Lopes, coordenadora de gestão agroindustrial; Hadegilton Aves Lopes, coordenador de gestão de planejamento e projetos. Para o Conselho Fiscal foram eleitos para o mandato de um ano os seguintes membros, Jorge Ferreira Lopes, Antônio Edinaldo Fernandes de Souza e Francisco Chagas Quadro Bamba e para suplentes, Maria Iris Alves Santos, Ronaldo Rodrigues Reis e Sebastião Felipe dos Santos (COOPCUNIÃ, 2019).

O principal projeto em desenvolvimento pela COOPCUNIÃ é o manejo do jacaré, desenvolvido para controlar a superpopulação desses répteis. Para o ano de 2020, a cooperativa planeja a comercialização dos produtos da sociobiodiversidade florestal local. A partir do estabelecimento de uma agroindústria, a castanha da Amazônia, frutas regionais, pescados e a carne do jacaré passarão a serem beneficiados ainda dentro da própria RESEX. Tornando, dessa forma, a primeira cooperativa na Amazônia a representar comercializar produtos industrializados ainda dentro da unidade de conservação (DIAS, 2018).

\section{MATERIAIS E MÉTODOS}

O método utilizado na presente pesquisa consistiu em uma adaptação da proposta de Souza (2019). Trata-se de uma abordagem exploratória, estabelecida por um estudo de caso combinado com método quantitativo, denominada mixed-methodology, estabelecida seguindo, neste trabalho, conforme os preceitos de Freitas e Jbbour (2011) e (Yin (2001).

Os dados quantitativos foram obtidos através da aplicação de formulários contendo questões objetivas e discursivas (Apêndice A) divididas em três blocos. O primeiro com questões abrange perguntas relacionadas ao perfil socioeconômico dos jovens (idade, escolaridade, economia e fonte de renda), o segundo e terceiro blocos com questões sobre: as atividades desenvolvidas no local, meio ambiente, uso dos recursos naturais, geração e gestão de resíduos sólidos, e a atuação dos jovens na cooperativa e na RESEX.

A aplicação do questionário ocorreu nos dias 31 de janeiro e 01 de fevereiro de 2020, na sede da escola Francisco Braga na comunidade da RESEX Lago do Cuniã, e na residência de alguns jovens que não estavam presentes na escola. Foram aplicados formulários a todos que se enquadravam nos seguintes critérios: ter entre 16 e 24 
PERCEPÇÃO SOBRE IMPACTOS SOCIOAMBIENTAIS: UM ESTUDO DE CASO NA RESEX LAGO DO CUNIÃ, PORTO VELHO, RONDÔNIA

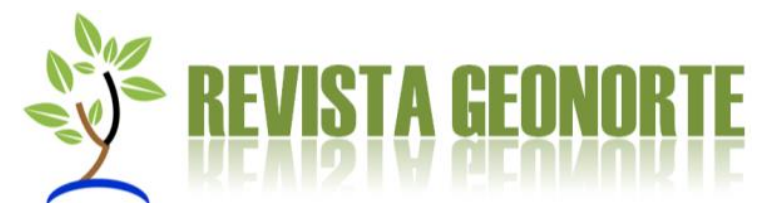

anos, ser sócio da COOPCUNIÃ e residir na RESEX Lago do Cuniã. Para realização da presente pesquisa foram utilizados: prancheta com questionários e caneta, conforme Figura 2. Os dados coletados foram tabulados e analisados, utilizando-se 0 Excel@ versão 2016.
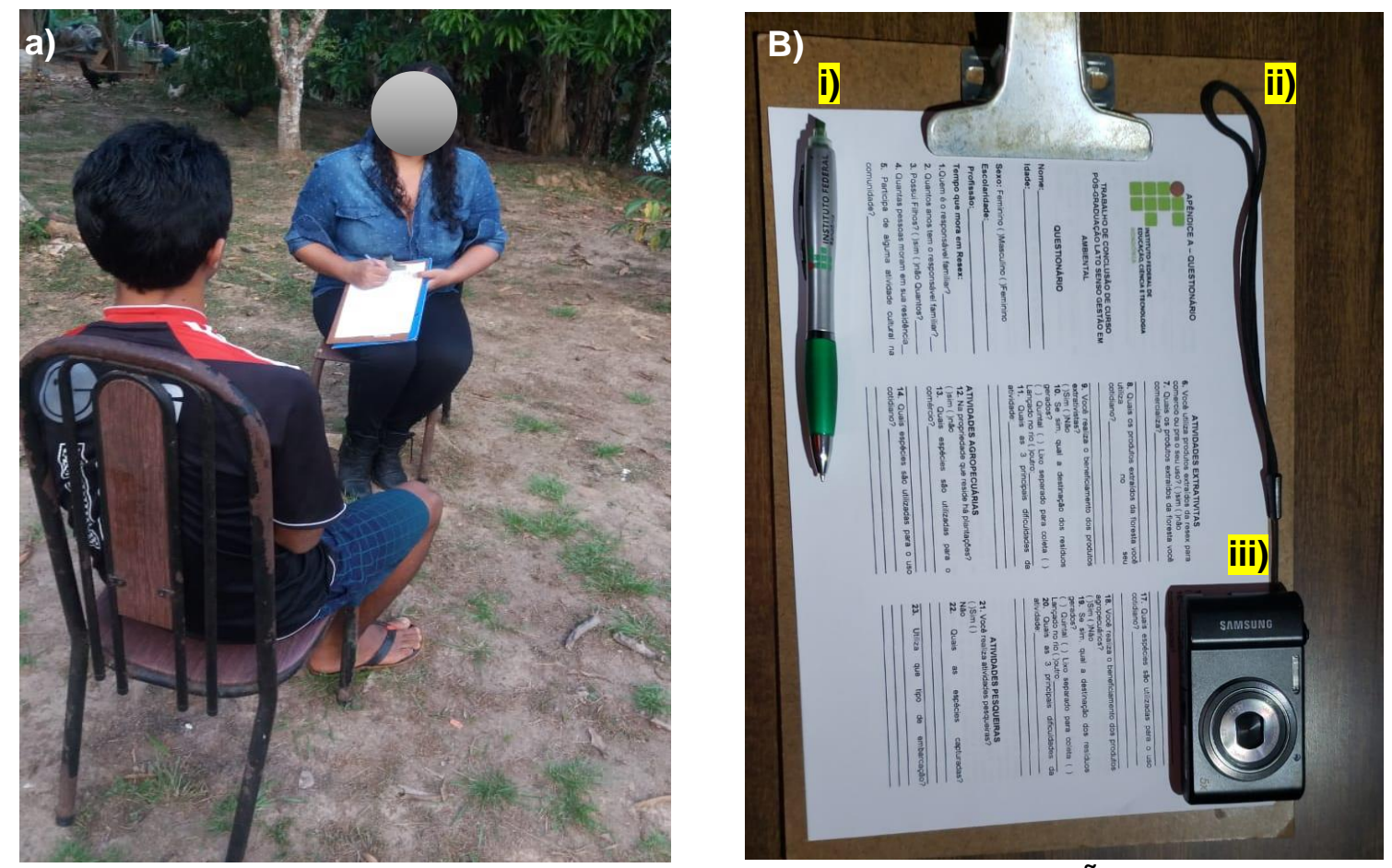

Figura 2. a) Entrevista concedida por jovem associado à COOPCUNIÃ; b) Material utilizado nas visitas a RESEX do Lago Cuniã, i) caneta esferográfica, ii) prancheta e iii) câmera fotográfica. Organização: Autores, 2021.

\section{RESULTADOS E DISCUSSÕES}

Os dados referentes à caracterização socioeconômica revelaram que apenas doze indivíduos, entrevistados são 6 do sexo masculino e 6 do sexo feminino, estão associados à COOOPCUNIÃ, apresentam idade de 16 a 24 anos e ainda são residentes na RESEX Lago do Cuniã. Sendo que desse montante $(83,33 \%)$ residem com seu país e $(16,67 \%)$ possuem sua própria família e têm sua própria casa. Em $(66,67 \%)$ o pai foi apontado como responsável pela liderança do lar e em apenas $(16,67 \%)$ o cônjuge e o próprio entrevistado foram designados como responsável pela garantia de renda e sustento familiar, apesar de $(33,33 \%)$ já terem filhos. Refletindo o padrão de residência e liderança do lar, a faixa etária dos chefes de família variou de 20 a 72 anos e a quantidade de indivíduos residentes na mesma casa variou entre 3 a 7 .

Com relação à ocupação e trabalho, $(66,67 \%)$ dos entrevistados declararam que a sua principal são os estudos, e $(25,00 \%)$ relataram que é a pesca e $(8,33 \%)$ disseram ser a fabricação da farinha. Logo, apesar de a COOPCUNIÃ ter trazido uma perspectiva de renda para esses jovens, chama a atenção o fato que nenhum dos 
jovens participantes da pesquisa, ter citado a cooperativa como fonte de renda. Fato que pode ser explicado devido à COOPCUNIÃ ter paralisado suas atividades no ano de 2016. O trabalho Fernandes (2014) é elucidativo a respeito. Segundo a autora, apesar da existência de capital social no adequado ao projeto do manejo Jacaré, foi constatada a existência, na unidade de conservação, outras iniciativas como o projeto de manejo do peixe Pirarucu, o turismo ecológico e beneficiamento da castanha, com capitação de recursos oriundos de financiamento Estatal e de compensações obras, na capital Porto Velho, com impactos socioambientais. Além, dos prejuízos gerados ao projeto do jacaré em decorrência da inundação da RESEX pelo Rio Madeira em 2014.

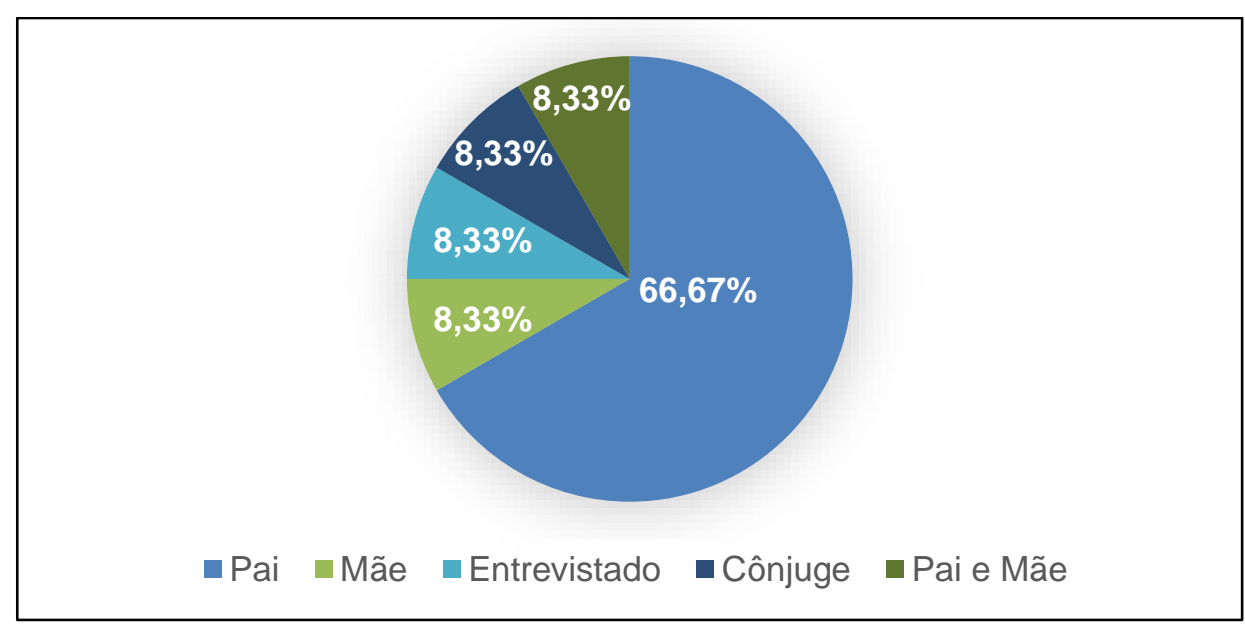

Figura 3. Responsável familiar dos jovens de 16 a 24 anos associados à COOPCUNIÃ e residentes na Resex Lago do Cuniã, Porto Velho, Rondônia. Fonte: elaborado pelos autores.

No que se refere à escolarização (83,33\%) dos entrevistados ainda não possui o ensino médio completo, sendo que $(41,67 \%)$ não concluíram o ensino fundamental, com mostra a Figura 4. Trata-se de indicadores preocupantes, uma vez que segundo a idade para a conclusão do ensino fundamental é de 14 anos, conforme explicam Puentes, Faleiro e Leornadi (2019). Logo, segundo as metas estabelecidas pelo Programa de Nacional de Educação (PNE) todos já deveriam terem concluído o nono ano. Uma possível explicação para este quadro pode estar relacionada ao conflito entre a jornada escolar e laboral, já que $(66,67 \%)$ afirmaram que horário vespertino de oferta para frequência escolar é incompatível com sua jornada de trabalho, seja por conta da sobreposição de horários, seja pelo cansado decorrente do trabalho demasiadamente esforçado.

Ao serem perguntado sobre a participação em alguma atividade cultural na Resex, a resposta mais obtida foi a frequência a igrejas, $(41,67 \%)$ dos entrevistados. O restante declara que participa de atividades culturais, somente quando tem algum evento na comunidade, como por exemplo, torneio de futebol ou festejos promovidos pelos próprios moradores. 


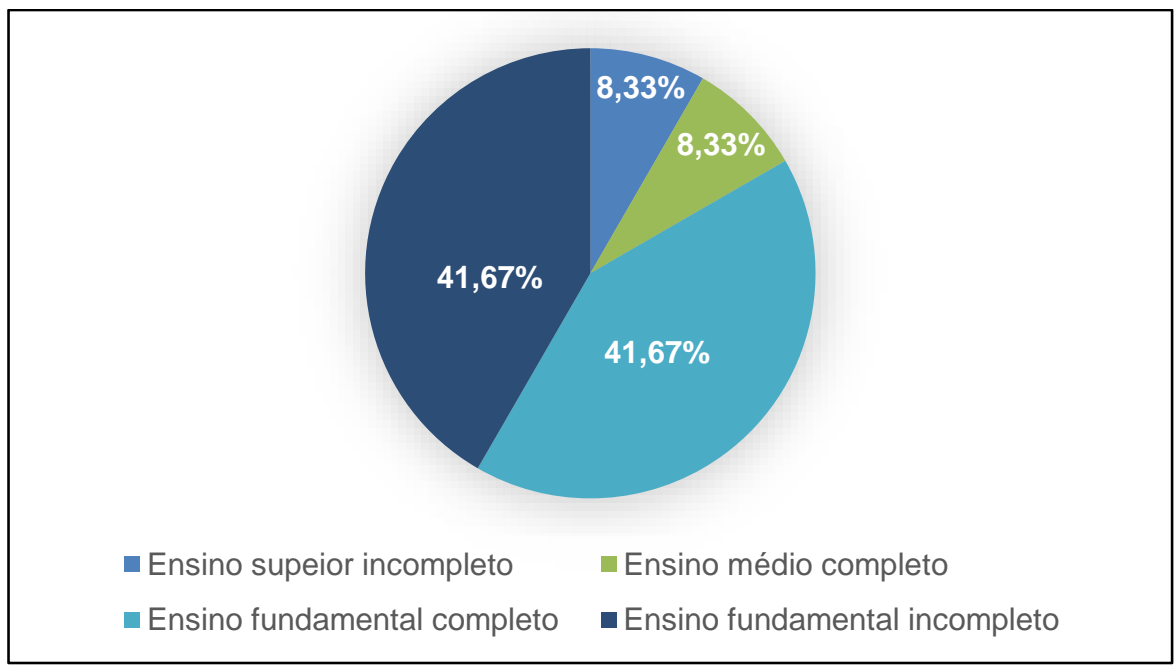

Figura 4. Escolarização dos jovens de 16 a 24 anos associados à COOPCUNIÃ e residentes na Resex Lago do Cuniã, Porto Velho, Rondônia. Fonte: elaborado pelos autores.

Em relação à composição da renda, (58,33\%) dos entrevistados apresentam como única fonte a venda de produtos extrativistas, agropecuários e pesqueiros comercializados através da COOPCUNIÃ e (33,33\%) complementam a renda através de auxílios governamentais, Bolsa Família e o Seguro Defeso no caso dos pescadores profissionais, o restante declara não apresentar renda. Porém, quando questionados sobre a mobilização dos jovens, associados à COOPCUNIÃ e residentes na RESEX Lago do Cuniã, todos afirmaram haver necessidade maior mobilização dos jovens na comunidade, sendo as reuniões, palestras e cursos de capacitação.

Sobre as atividades extrativistas, verificou-se que (83,33\%) dos participantes da pesquisa afirmaram comercializar algum dos recursos naturais disponíveis na unidade de conservação para sustento e manutenção de suas famílias. Os de origem vegetal mais citados no uso cotidiano foram: a castanha da Amazônia (Bertholletia excelsa), frutas regionais e espécies oleaginosas como a bacaba (Oenocarpus bacaba), e a Andiroba (Carapa guianensis), utilizadas na cura de algumas doenças, Figura 5a. Já as espécies mais citadas, comercializadas por eles, foram o açaí (Euterpe oleracea) e castanha da Amazônia, Figura 5b. Em relação ao beneficiamento desses produtos, $(91,67 \%)$ dos entrevistados relataram que praticam o despolpa de frutas para o armazenamento objetivando tanto o consumo como a comercialização seja na comunidade ou até mesmo no comércio de Porto Velho, Rondônia. Quanto à destinação dos resíduos gerado $(41,67 \%)$ afirmaram queimar, $(41,67 \%)$ descartam no quintal e (16,67\%) utilizam como adubo para as plantas, através da prática de compostagem. As três principais dificuldades relatadas para o exercício do extrativismo vegetal dos entrevistados foram: a falta de materiais adequados, dificuldade na logística de comercialização e o baixo valor agregado no produto vendido. 
PERCEPÇÃO SOBRE IMPACTOS SOCIOAMBIENTAIS: UM ESTUDO DE CASO NA RESEX LAGO DO CUNIÃ, PORTO VELHO, RONDÔNIA
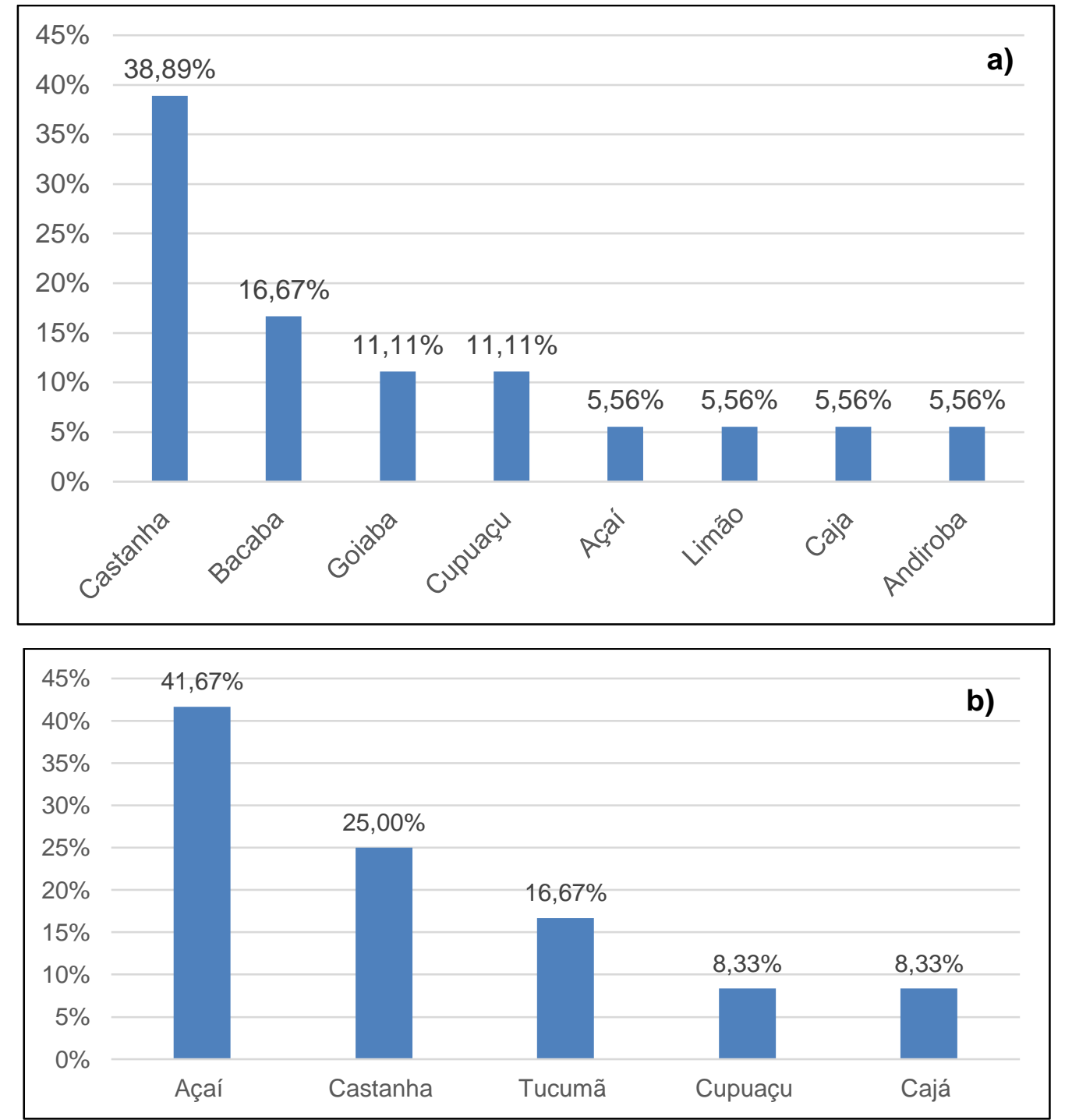

Figura 5. Principais produtos extrativistas utilizados a) no cotidiano e b) comercializados pelos jovens associados à COOPCUNIÃ e residentes na RESEX Lago do Cuniã, Porto Velho Rondônia. Fonte: elaborado pelos autores.

O extrativismo animal pesqueiro é praticado por $(58,33 \%)$ dos entrevistados, mas apenas (33,33\%) possuem carteira profissional. As espécies listadas como mais capturadas são: Tucunaré (Cichlaocellaris), Pacu (Piaractusmesopotamicus) e Piau (Leporinusfreiderici), como demonstrado a Figura 6. A principal embarcação utilizada na atividade pesqueira, mencionada pelos jovens nas entrevistas, foi a canoa $(41,66 \%)$, seguida bote $(8,33 \%)$ e rabeta $(8,33 \%)$. Os apetrechos mais citados como utilizados pelos entrevistados para pescar foram a malhadeira $(50,00 \%)$, linhas com anzóis (33,34\%) e a zagaia com (16,67\%). Quando perguntados sobre a área de atuação, todos citaram o lago do Cuniã sem, no entanto, a definição de um local específico. Quanto ao beneficiamento do pescado, somente (16,67\%) dos entrevistados afirmaram o que fazem antes da comercialização. Ao serem questionados a respeito dos resíduos gerados, (8,33\%) relataram que jogam no quintal para os outros animais se alimentarem e $(8,33 \%)$ disseram que queimam em 
conjunto com outros lixos. As três principais dificuldades, listadas pelos entrevistados, no exercício da atividade pesqueira, foram: ficar sentado muito por tempo desconfortável e ficar exposto ao sol a uma temperatura elevada.

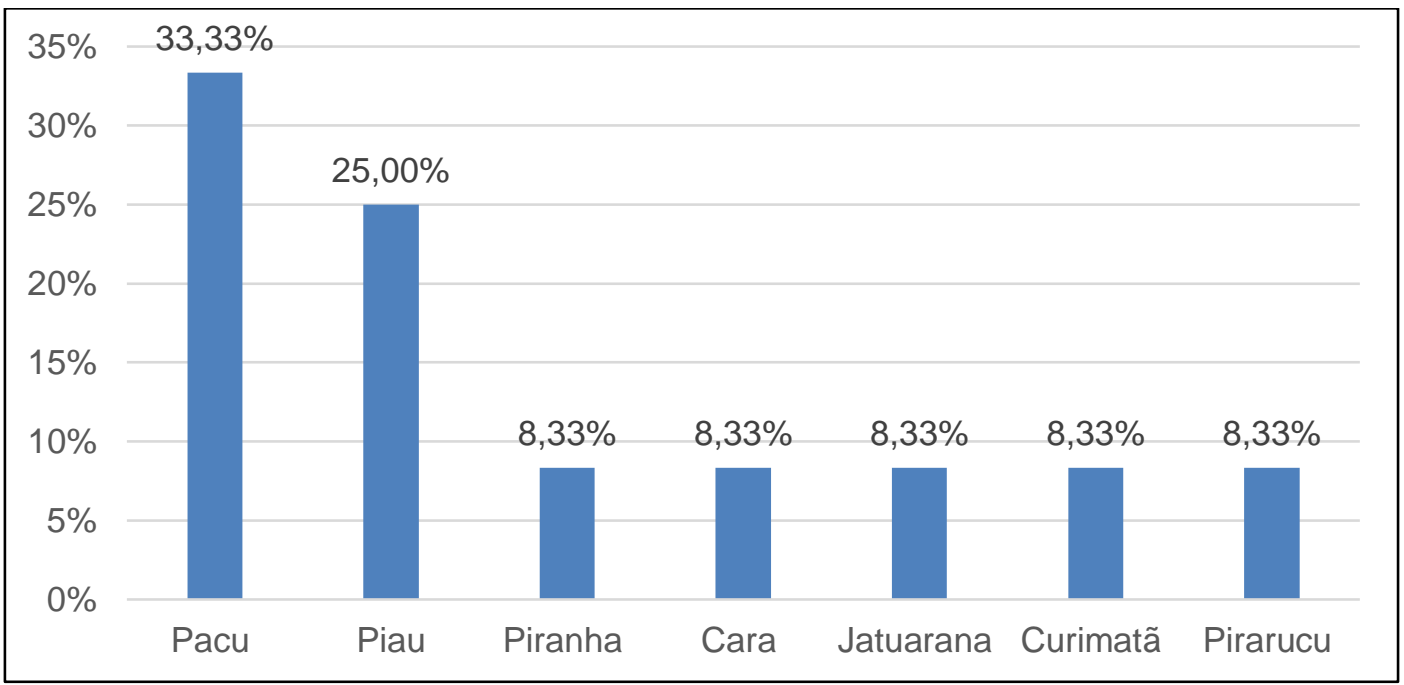

Figura 6. Principais produtos de extrativismo animal utilizados no cotidiano e comercializados pelos jovens associados à COOPCUNIÃ e residentes na RESEX Lago do Cuniã, Porto Velho Rondônia. Fonte: elaborado pelos autores.

Quanto às atividades agropecuárias $(91,67 \%)$ dos entrevistados afirmaram que nas propriedades onde residem há plantação de mandioca (Manihot esculenta) e atividade pecuarista. A mandioca é utilizada tanto para consumo familiar como para comercialização. As principais criações animais citadas como utilizadas para consumo foram o frango caipira $(50,00 \%)$, patos $(25 \%)$, peixes $(8,33 \%)$ e gado de corte $(8,33 \%)$. Já as destinadas à venda foram: também o frango caipira $(50,00 \%)$ e patos $(16,67 \%)$. Em relação ao beneficiamento dos produtos agropecuários, $(75,00 \%)$ disseram que fazem a transformação da mandioca em farinha. Quando perguntados sobre destinação dos resíduos pela atividade agropecuária, $(83,33 \%)$ relataram que jogam os resíduos no quintal ou queimam e $(8,33 \%)$ declaram que alimentam as criações. Como pode ser observado na Figura 7. Não houve relatos a respeito das principais dificuldades encontrada na atividade agropecuária. 


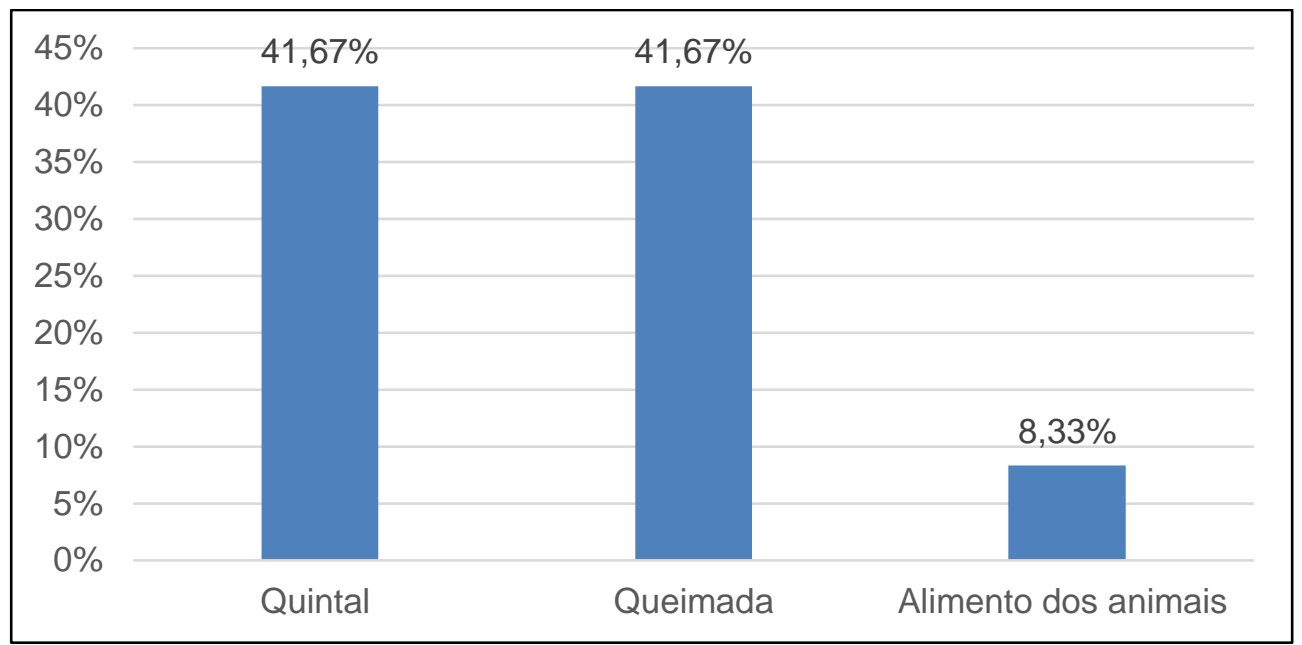

Figura 7. Destinação dos resíduos gerados na atividade agropecuária nas propriedades onde residem os jovens associados à COOPCUNIÃ e residentes na RESEX Lago do Cuniã, Porto Velho Rondônia. Fonte: elaborado pelos autores.

A avaliação da percepção ambiental revelou que (50,00\%) dos entrevistados não foram capazes de explicar o significado de RESEX e de impacto ambiental. Os demais tiveram como tronco de sustentação para a primeira definição o uso sustentável e relacionaram impacto ambiental a um dano negativo a natureza. Sobre a percepção dos impactos ao meio ambiente existente na unidade de conservação, os mais citados foram: enchente $(83,33 \%)$, queimada $(66,67 \%)$, poluição do rio $(41,67 \%)$, pesca predatória e caça com (33,33\%), contaminação do solo $(25,00 \%)$, desmatamento, deslizamento e lixo com (8,33\%) cada ${ }^{1}$, como pode ser observado na Figura 8 . Por conseguinte, nota-se que apesar da dificuldade de reconhecer e definir conceitos teóricos, jurídicos e acadêmicos, os entrevistados possuem percepção ambiental consonante com o definido por Botega e Lindino (2017), isto é, como fruto das observações individuais do meio ambiente e das relações sociais. No entanto, apresentam confusão entre as causas e o impacto propriamente dito, já que a maior parte apontou queimada como impacto ambiental e não fumaça ou a poluição do ar.

Depreende-se, portanto, a necessidade de implantação de programas de educação ambiental para que o conhecimento empírico adquirido através da percepção do meio ambiente, por parte dos jovens associados à COOPCUNIÂ e residentes na RESEX Lago do Cuniã, possam ser aproximar dos formais e como isso auxiliar na Formação cidadãos conscientes seus direitos e deveres em escola local e planetária, com base no espírito crítico e inovador, promovendo a transformação e a construção da sociedade em uma perspectiva holística, como preconiza Gadotti (2000) no referente a importância do educação ambiental como instrumento de transformação social.

\footnotetext{
${ }^{1}$ A soma dos valores supera os $100 \%$ em virtude terem sido considerado o impacto citado em relação ao total dos entrevistados, logo, queimada foi mencionado por 8, poluição dos rios por 5, pesca predatória por 4, contaminação do solo por 3 e deslizamento e lixo, cada, por 1 entrevistado.
} 


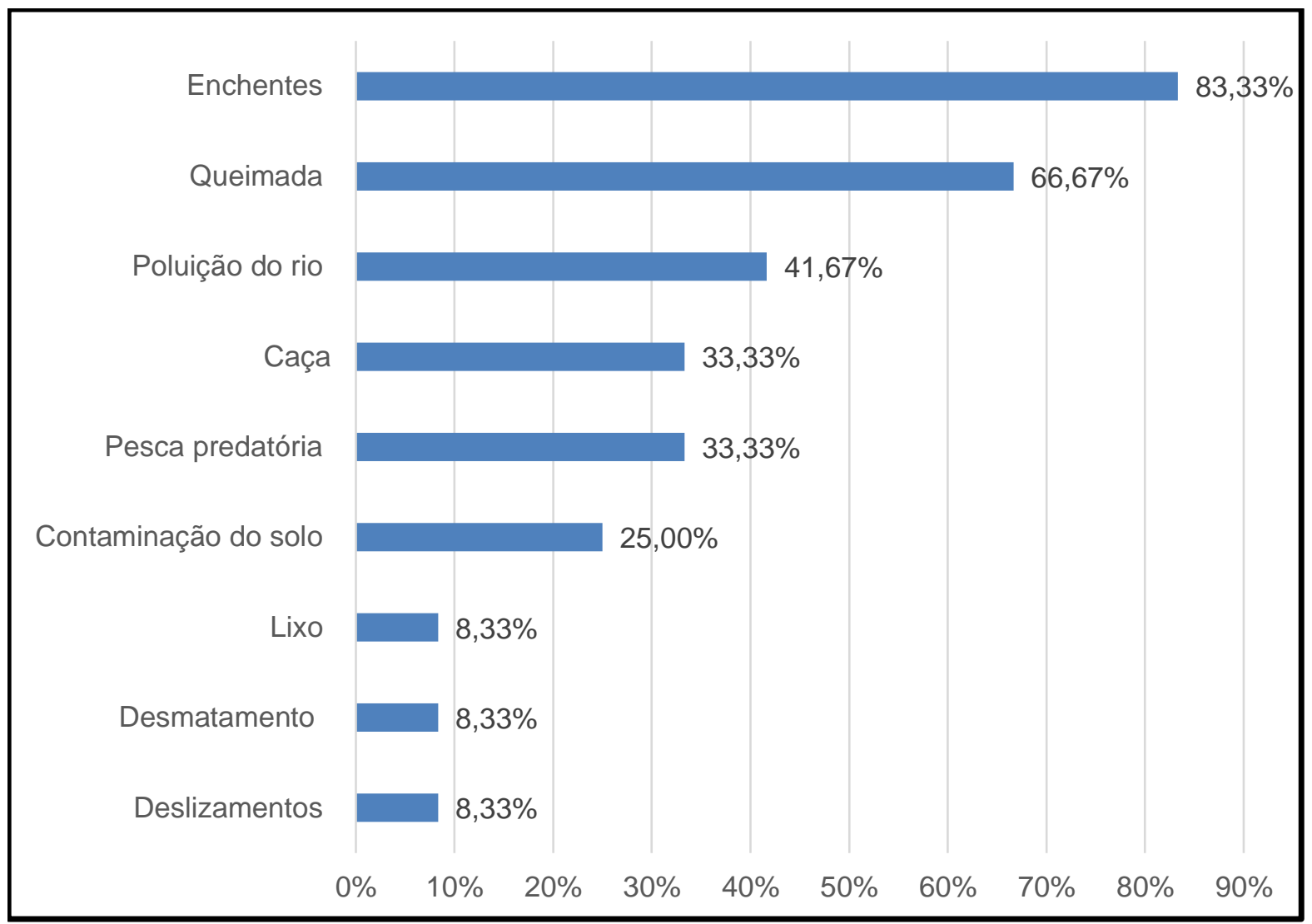

Figura 8. Percepção dos principais impactos ambientais pelos jovens de 16 a 24 anos associados à COOPCUNIÃ e residentes na RESEX Lago do Cuniã, Porto Velho, Rondônia.

Fonte: elaborado pelos autores.

Com relação aos resíduos sólidos, verificou-se a não existência de um sistema de coleta na unidade de conservação como um fator que interfere diretamente na destinação do lixo produzido nas residências dos entrevistados, já que $(91,67 \%)$ declaram que o lixo doméstico é queimado e (50,00\%) sequer sabem definir coleta seletiva. Comportamento semelhante foi observado por Souza (2019) ao estudar a RESEX Marinha Cuinarana em Magalhãs Barata, no Pará. Segundo a autora, a falta de um sistema de coleta foi responsável pela percepção do inadequado descarte dos resíduos como principal impacto ambiental naquela unidade de conservação, sendo inclusive fator de congregação e mobilização social por parte das mulheres.

Dessa forma, os jovens participantes da presente pesquisa apresentaram alta consciência ambiental, entendida conforme Bedante e SLongo (2004). Assim, observou-se alta capacidade de posicionamento, favorável ou contrário, frente aos assuntos inerentes ao meio ambiente. Porém, a falta de um sistema de gerenciamento de resíduos na RESEX influencia diretamente na baixa capacidade, dos entrevistados, em tomar decisões considerando o impacto ambiental de suas ações, haja vista a predominância da queimada como principal mecanismo de eliminação dos residuos sólidos.

Como pode ser observado na Figura 9, a falta de um sistema de gerenciamento e tratamento, ainda nutre relação com a percepção, dos participes da pesquisa, sobre 
os problemas causados pelo lixo, uma vez que reconhecem a poluição da água $(75,00 \%)$, alagamentos $(66,67 \%)$, queimadas $(66,67 \%)$, proximidades de animais e poluição do ar $(58,33 \%)$ e proliferação de vetores de doença $(50,00 \%)$, logo todos problemas relacionados ao manejo inadequado dos resíduos domésticos. Todavia, é possível verificar que os jovens associados à COOPCUNIÃ e residentes na RESEX Lago do Cuniã, em $(91,67 \%)$ reconhecem no reaproveitamento de resíduos uma possível fonte de renda, principalmente a partir do reaproveitamento de latas de bebidas gasificas e alcoólicas, além das garrafas de Polietileno tereftalato (PET) que já são reutilizadas na comunidade para outras finalidades, principalmente o armazenamento de água potável.

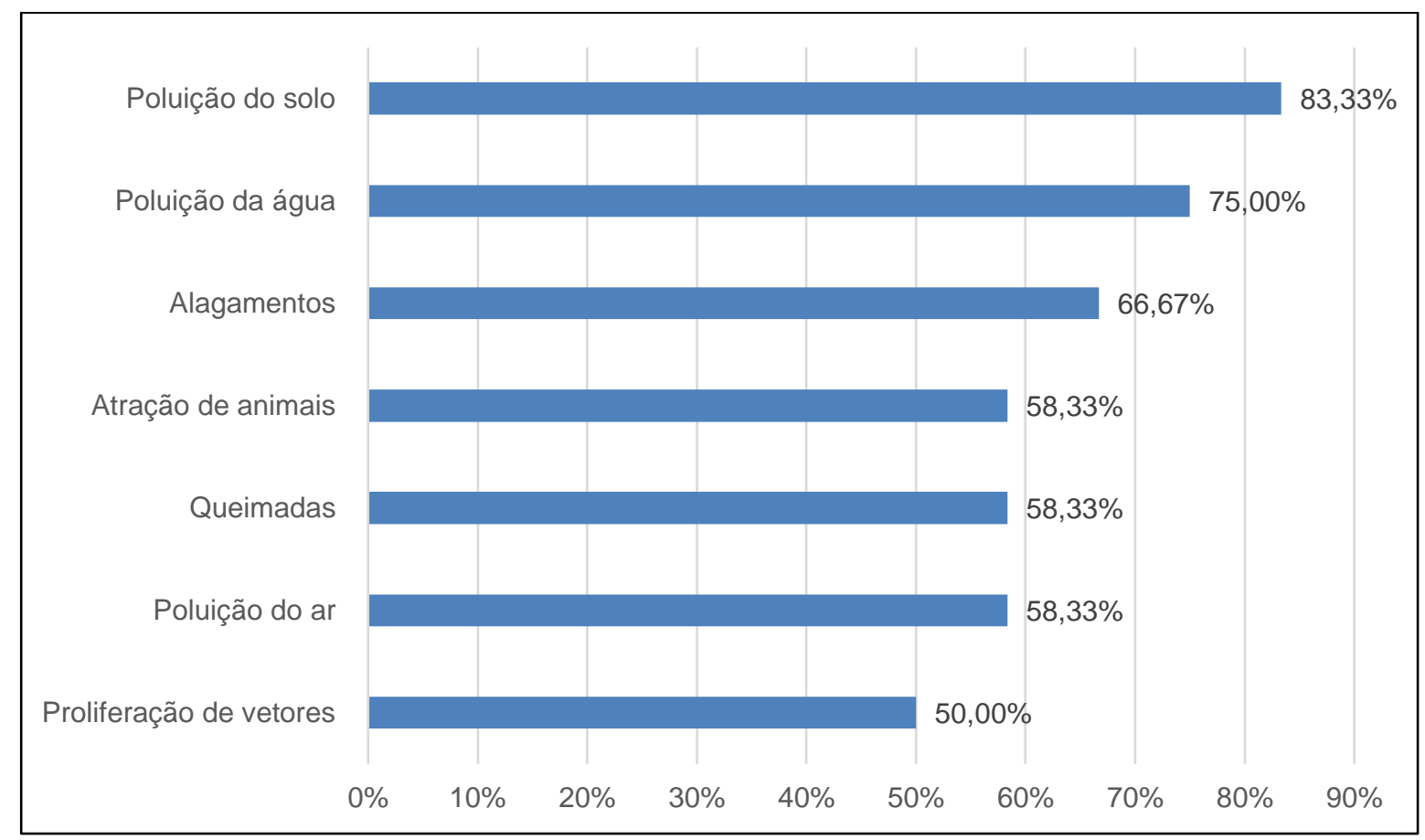

Figura 9. Percepção dos principais problemas ambientais causados pelo lixo pelos jovens de 16 a 24 anos associados à COOPCUNIÃ e residentes na RESEX Lago do Cuniã, Porto Velho, Rondônia. Fonte: elaborado pelos autores.

A respeito das práticas de conservação do ambiente aquático, $(91,67 \%)$ e $(66,67 \%)$, respectivamente, dos entrevistados, acreditam que os resíduos domésticos e os oriundos da atividade extrativista e agropecuária possam interferir na qualidade dos recursos hídricos utilizados por eles. Bem como, as principais práticas conservacionistas listadas como parte do cotidiano dos participantes da pesquisa foram: o ensino dos visitantes da RESEX sobre a correta maneira de descarte do lixo e a conservação das matas ciliares, como o principal motivo de evitar os deslizamentos, desbarrancamentos e até mesmo a poluição das águas fluviais. Desse modo, observa-se a população local possui aguda percepção ambiental, sobre os impactos gerados por suas ações aos igarapés, rios e lagos locais, mas a inexistência de um sistema de coleta e destinação adequada dos resíduos impede que a população modifique seus hábitos. Situação semelhante à encontrada por Botega e Lindino (2017) ao estudarem a percepção ambiental e resíduos sólidos na cidade 
Santa Helena, Paraná, apesar de o trabalho deles terem sido realizado em ambiente urbano. De acordo com autores, somente, a promoção de espaço de informação que possam propiciar momentos de reflexão, crítica e comprometimento pelos sujeitos envolvidos, para que os mesmos possam atuar de forma responsável no meio ambiente. Por conseguinte, a Educação Ambiental é fundamental nesse cenário, desde que se trabalhe a ideia de complexidade do tema, de modo a discutir realmente os problemas ambientais que vivenciamos em nossa sociedade (local e global).

\section{CONCLUSÃO OU CONSIDERAÇÕES FINAIS}

Os jovens de 16 a 24 anos associados à COOPCUNIÃ e ainda residentes na RESEX Lago do Cuniã, em sua maioria, ainda não são responsáveis pela liderança do lar. Têm como principal ocupação o estudo, apesar de apresentarem baixa escolarização, principalmente por terem de parte de sua rotina ocupadas com atividades extrativistas e agropecuárias. Além, da baixa disponibilidade de atividades culturais.

Com relação à ocupação e trabalho, observou-se que $(83,33 \%)$ do rendimento dos entrevistados é proveniente das atividades extrativista e agropecuário por iniciativa deles. Já a COOPCUNIÃ, apesar de se configurar como alternativa local de geração de renda, apresenta suas atividades paralisadas desde 2016 e hoje desenvolve atividades relacionadas ao abate do jacaré com seus respectivos beneficiamentos. Logo, no momento de realização da presente pesquisa, os principais produtos comercializados e que garantem fonte de renda, são a castanha da Amazônia, o frango caipira, o peixe e a farinha da mandioca, sendo utilizados também como parte da dieta alimentar dos entrevistados.

A avaliação da percepção ambiental possibilitou verificar que a falta de gestão e tratamento dos resíduos interfere diretamente na maneira como os entrevistados concebem a sua relação e da comunidade com o meio ambiente. Assim, é preocupante que $(50,00 \%)$ não consigam significar RESEX e impacto ambiental e que $(91,67 \%)$ utilizem a queimada como principal meio de destinação do lixo. Em contrapartida, os jovens partícipes da pesquisa, conseguiram reconhecer os principais impactos ambientais que afetam direta e indiretamente a comunidade, bem como os decorrentes pela falta de um sistema de tratamento de resíduos na unidade de conservação do Lago do Cuniã.

Portanto, a presente pesquisa demonstra a necessidade da instalação de um sistema de gerenciamento e tratamento de resíduos, acompanhada pela implantação de programas de educação ambiental, valorização do cooperativismo e de um sistema educacional compatíveis com a realidade cotidiana dos jovens. 
PERCEPÇÃO SOBRE IMPACTOS SOCIOAMBIENTAIS: UM ESTUDO DE CASO NA RESEX LAGO DO CUNIÃ, PORTO VELHO, RONDÔNIA

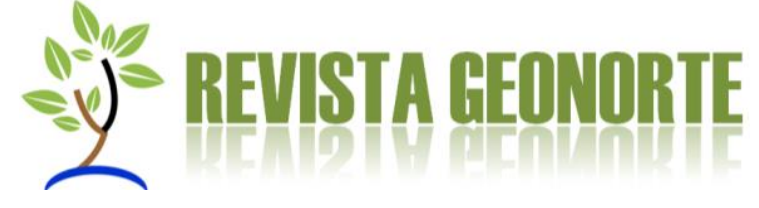

\section{REFERÊNCIAS}

ALMEIDA, J.; PREMEBIDA, A. Histórico, relevância e explorações ontológicas da questão ambiental. Sociologias, Porto Alegre, ano 16, n. 35, p. 14-33, jan./abr. 2014.

ALMEIDA, J. O campo da pesquisa e das ações sobre o meio ambiente. Porto Alegre: PGDR/UFRGS, 2004.

BRASIL. Resolução CONAMA n. 001. 1986. Dispõe sobre critérios básicos e diretrizes gerais para a avaliação de impacto ambiental. Disponível em: http://www2.mma.gov.br/port/conama/res/res86/res0186.html. Acesso em: 11 nov. 2019.

BEDANTE, G. N; SLONGO, L. A. O comportamento de consumo sustentável e suas relações com a consciência ambiental e a intenção de compra de produtos ecologicamente embalados. EMA - Encontro de Marketing, 1. Em: Anais ..., Atibaia, SP: Anpad, 2004.

BOTEGA, J. L.; LINDINO, T.C. Percepção Ambiental e Gerenciamento dos Resíduos Sólidos em Residências na Cidade de Santa Helena, PR. Pleiade, 11(22): 99-110, jul/dez.2017.

COOPERATIVA DE PESCADORES, AQUICULTORES, AGRICULTORES E EXTRATIVISTAS DA RESEX LAGO DO CUNIÃ (COOPCUNIÃ). Porto Velho. Ata da Assembleia Geral Ordinária. P123-5.

COSTA, R. Geniany S.; COLESANTI, M. A contribuição da percepção ambiental nos estudos das áreas verdes. Raega-O Espaço Geográfico em Análise, v. 22, 2011.

DERANI, C. Direito ambiental econômico. 2. ed. São Paulo: Max Limonad, 2001, p. 87.

PAULA, E. M. S.; SILVA, E. V. da.; GORAYEB, A. Percepção Ambiental e dinâmica geoecológica: premissas para o planejamento e gestão ambiental. Revista Sociedade \& Natureza, Uberlândia, v. 26, n. 3, p. $511-518.2014$.

DIAS, M. I.S. Gestão Participativa e compartilhada: um modelo para as cooperativas da Agricultura Familiar. Curitiba: CRV, 2018. 224 p.

FERNANDES, P. B. S. Dimensões do capital social em empreendimento coletivo: um estudo de caso no projeto jacaré na reserva extrativista lago do Cuniã em Rondônia. 2014. 115 f. Dissertação (Mestrado em Administração), Fundação Universidade Federal de Rondônia, Porto Velho, 2014.

FERREIRA, Carolina Peixoto. Percepção ambiental na Estação Ecológica de JuréiaItatins. Dissertação (Mestrado em Ciência Ambiental) - Universidade de São Paulo. São Paulo, 2005. 
PERCEPÇÃO SOBRE IMPACTOS SOCIOAMBIENTAIS: UM ESTUDO DE CASO NA RESEX LAGO DO CUNIÃ, PORTO VELHO, RONDÔNIA

FREITAS, W. R. S.; JABBOUR, C. J. C. Utilizando Estudo de Caso(s) como Estratégia de Pesquisa Qualitativa: boas práticas e sugestões. Estudo e Debate, v. 18, n. 2, p. 07-22, 2011.

GADOTTI, M. Perspectivas atuais da Educação. São Paulo: Perspectiva, 2000; 2(14):3-11.

GIBSON, J. The perception of the visual world. Connecticut: Greenwood Press Publishers, 1974. 224 p.

GODOY, A. S. Revendo a aula expositiva. In: MOREIRA, D. A. (Orgs). Didática do ensino superior: técnicas e tendências. São Paulo: Pioneira, 1997. p.75-82

IBGE - INSTITUTO BRASILEIRO DE GEOGRAFIA E ESTATÍSTICA. Censo Demográfico 2010: Características gerais da população - conceitos e definições tabelas adicionais. Rio de Janeiro: IBGE, 2011

ICMBio - Instituto Chico Mendes de conservação da biodiversidade. Plano de Manejo da Reserva extrativista lago do Cuniã. 2018. Disponivel em< https://www.icmbio.gov.br/portal/images/stories/plano-demanejo/plano de manejo da resex lago do cunia 2018.pdf>. Acesso em 20 de set. 2019

MELAZO, G.C. A percepção ambiental e educação ambiental: uma reflexão sobre asrelações interpessoais e ambientais no espaço urbano. Olhares \&Trilhas. Uberlândia, Ano VI, n. 6, p. 45-51, 2005.

PACHECO, E; SILVA, H. P. Compromissos epistemológicos do conceito de percepção ambiental. In: CONGRESSO DE ECOLOGIA DO BRASIL, 7., 2005, Caxambu. Anais. Disponível em: <http://www.ivt-j.net/sapis/2006/pdf/EserPacheco.pdf>. Acesso em: 09 jun. 2019.

PUENTES, R.V.; FALEIRO, W.; SANTOS L. E. O ensino médio brasileiro: análise de documentos oficiais. In: Puentes, V. R.; Longarezi, A. M.; Aquino, O. F. Ensino Médio estado atual, políticas e formação de professores, estado atual, políticas e formação de professores. Uberlândia: EDUFU, 2019.

OLIVEIRA, K. A.; CORONA, H. M. P. A percepção ambiental como ferramenta de propostas educativas e de políticas ambientais. Revista Científica ANAP Brasil, v. 1, n. 1, p. 53-72, 2008.

RIBEIRO, L. M. O papel das representações sociais na educação ambiental. Dissertação de Mestrado, pela Pontifícia Universidade Católica. 2004. 199f. Dissertação (Mestrado em Educação), Departamento de Educação Programa de PósGraduação em Educação. Rio de Janeiro, 2003.

RONDÔNIA. Secretaria de Estado do Desenvolvimento Ambiental. Atualização da 
Cartografia Básica, Porto Velho. Porto Velho: Zoneamento Socioeconômico e Ecológico, 2002.

SANTOS, R. G. Impactos Socioambientais à Margem do Rio São Francisco: um estudo de caso. 2008. 194 f. Dissertação (Mestrado em Geografia), Universidade de São Paulo, São Paulo, 2008.

SÁNCHEZ, Luis Enrique. As etapas iniciais do processo de avaliação de impacto ambiental. In: GOLDENSTEIN, S. et al (org). Avaliação de impacto ambiental. São Paulo: Secretaria do Meio Ambiente, 1999.

SILVA, R. V. da.; SOUZA, C. A. de.; BAMPI, A. C. Os olhares dos pescadores profissionais e proprietários comerciais, sobre o Rio Paraguai em Cáceres, Mato Grosso. Revista Brasileira de Ciências Ambientais, São Paulo, v.1, n. 32, p.24 -41, 2014.

SHIRAISHI, Juliana Costa. Conflitos Ambientais em Unidades de Conservação: Percepções sobre a Reserva Biológica da Contagem, DF: 2011. 115 f. Dissertação (Mestrado) - Curso de Desenvolvimento Sustentável, Centro de Desenvolvimento Sustentável, Universidade de Brasília, Brasília, 2011.

SOUZA, F. V. Percepção de Mulheres sobre os impactos socioambientais: estudo de caso da Resex Marinha Cuinarana, Magalhães Batata-PA. 2019. 54 f. Trabalho de Conclusão de Curso (Monografia). Universidade Federal Rural da Amazônia (Campus Universitário Belém, 2019.

YIN. R. K. Estudo de caso: planejamento e métodos. 2. ed. São Paulo: Bookman, 2001. 200p.

VALDANHA, N. D. Os filhos do Lago do Cuniã: educação escolar em uma reserva extrativista da Amazônia. 2014. 223 f. Dissertação (mestrado) - Universidade Estadual Paulista Júlio de Mesquita Filho, Faculdade de Ciências e Letras (Campus de Araraquara), 2014. 